University for Business and Technology in Kosovo

UBT Knowledge Center

UBT International Conference

2017 UBT International Conference

Oct 28th, 9:00 AM - 10:30 AM

\title{
The Influence of Division of Amlodipine Tablets on their Efficacy and Stability
}

\author{
Brunilda Myftari \\ University of Medicine, Tirana, brunaph@yahoo.com \\ Enxhi Andrea \\ University of Medicine, Tirana \\ Elton Myftari \\ University of Medicine, Tirana \\ Ledjan Malaj \\ University of Medicine, Tirana
}

Follow this and additional works at: https://knowledgecenter.ubt-uni.net/conference

Part of the Medicine and Health Sciences Commons

\footnotetext{
Recommended Citation

Myftari, Brunilda; Andrea, Enxhi; Myftari, Elton; and Malaj, Ledjan, "The Influence of Division of Amlodipine Tablets on their Efficacy and Stability" (2017). UBT International Conference. 286.

https://knowledgecenter.ubt-uni.net/conference/2017/all-events/286

This Event is brought to you for free and open access by the Publication and Journals at UBT Knowledge Center. It has been accepted for inclusion in UBT International Conference by an authorized administrator of UBT Knowledge Center. For more information, please contact knowledge.center@ubt-uni.net.
} 


\title{
The Influence of Division of Amlodipine Tablets on Their Efficacy and Stability
}

\author{
Brunilda Myftari ${ }^{1}$, Enxhi Andrea, Elton Myftari, Ledjan Malaj \\ ${ }^{1}$ Department of Pharmacy, Faculty of Medicine, University of Medicine, Rr. \\ Dibrës, Nr. 374, 1005, Tirana, Albania \\ brunaph@yahoo.com
}

\begin{abstract}
The purpose of this study is to identify the implication of tablet division by patients on their efficacy. It aims to show if it affects or not the percentage of the active substance in Amlodipine tablets $10 \mathrm{mg}$. It was used besylate amlodipine as RS, 3 different productions of Amlodipine tablets have been kept in similar conditions as a patient can do and were analysed via HPLC method as described in the Ph. Eur. 2011, every 7 days for 4 weeks. All productions after division showed no visual changes. Only halves of sample A fulfill the criteria for RD \pm $7.5 \%$. From the results obtained, it was noted that there was a decrease in the percentage of the active substance, as follows in sample A resulted to be $83.6 \%$, in sample B $84.37 \%$ and sample $\mathrm{C} 83.75 \%$. Based on these results, it is concluded that tablet division is a process that significantly affects the percentage of the tablet's active substance,which implies that the patient doesn't receive the required dose for treatment and the success of therapy is in doubt. The division of amlodipine tablets is economically convenient, but is a practice that should be avoided.
\end{abstract}

Keywords: amlodipine, tablet division, efficacy, stability.

\section{Introduction}

The practice of tablet division is a very widespread phenomenon in Albania. Patients do it for two reasons mainly, first financial reasons and second under their physician advice. Due to every year changes in the List of Reimbursed Drugs in the Republic of Albania, the mass of payment by the patient changes and people choose to take the form/dose that allows them to pay less. MD's recommend the division of tablets when a certain dose is not registered in Albania or when the import of it delays. Patient can divide the tablets by hand or with a kitchen knife. Tablets may have or not an imprinted division line. Unfortunately, this practice may lead to unaccomplished treatment or even deteriorate the health situation of the patient. The purpose of this study is to determine how much this practice affects the efficacy and stability of tablets within 1 month period. It has been choosen Amlodipine tablet because it is a drug used on a chronic therapy, it is part of Reimbursement List in the Republic of Albania and from financial point of view Amlodipine tablets $10 \mathrm{mg}$ are more convinient than those of $5 \mathrm{mg}$.

\section{Materials and Methods}

It was used besylate amlodipine as RS, three different productions of Amlodipine tablets bought directly in a community pharmacy. It was selected the method based on the HPLC analysis of the solutions obtained by dissolution of amlodipine in methanol as described in the European Pharmacopoeia 2011. HPLC apparatus Varian, Column size $1=0.25 \mathrm{~m}, \varnothing=4 \mathrm{~mm}$; stationary 
phase: silica gel for chromatography; mobile phase is a mixture $30: 70 \mathrm{~V} / \mathrm{V}$ ammonium acetate and methanol HPLC grade, $\lambda=237 \mathrm{~nm}$, flow rate $1.5 \mathrm{ml} / \mathrm{min}$. This was an ongoing analysis for four weeks. The divided tablets have been kept in similar conditions as a patient can do. It was important the medium weight of divided tablets and relative deviation calculated with the following formulas:

$\frac{P 1+P 2+P 3+P 4+P 5+P 6+P 7+P 8+P 9+P 10}{10}$

SHR $(\%)=\frac{P \text { min }-P \text { mes }}{P \text { mes }} \times 100 \% \quad$ SHR $(\%)=\frac{P \text { max }-P \text { mes }}{P \text { mes }} \times 100 \%$

The percentage of active ingredient and the correction factor was determined as follows:

$$
\begin{gathered}
\mathrm{P}_{\mathrm{MA}}=408.879 \mathrm{~g} / \mathrm{mol} \quad \mathrm{P}_{\mathrm{MAB}}=567.1 \mathrm{~g} / \mathrm{mol} \\
\mathrm{f}=\mathrm{P}_{\mathrm{MA}} / \mathrm{P}_{\mathrm{MAB}}=408.879 / 567.1=0.72
\end{gathered}
$$

it can be said that $\mathrm{m}_{\mathrm{A}}=0.72 \times \mathrm{m}_{\mathrm{MAB}}$.

The solution for analysis was prepared as follows:

$10 \mathrm{mg}$ amlodipine $\rightarrow 50 \mathrm{ml}$ methanol

$\mathrm{C}=32 \mu \mathrm{g} / \mathrm{ml}$

$$
\stackrel{\downarrow}{4 \mathrm{ml}} \rightarrow 25 \mathrm{ml} \text { methanol }
$$

The same method was used to prepare the solution of samples for the determination of the percentage of active ingredient and for impurities.

\section{Results}

The organoleptic control after division showed no changes for all three productions. (See table 1) Only halves of sample A fulfill the pharmacopoeia criteria for RD $\pm 7.5 \%$. 
Table 1. Data gathered from quality control before and after division of $10 \mathrm{mg}$ amlodipine tablets.

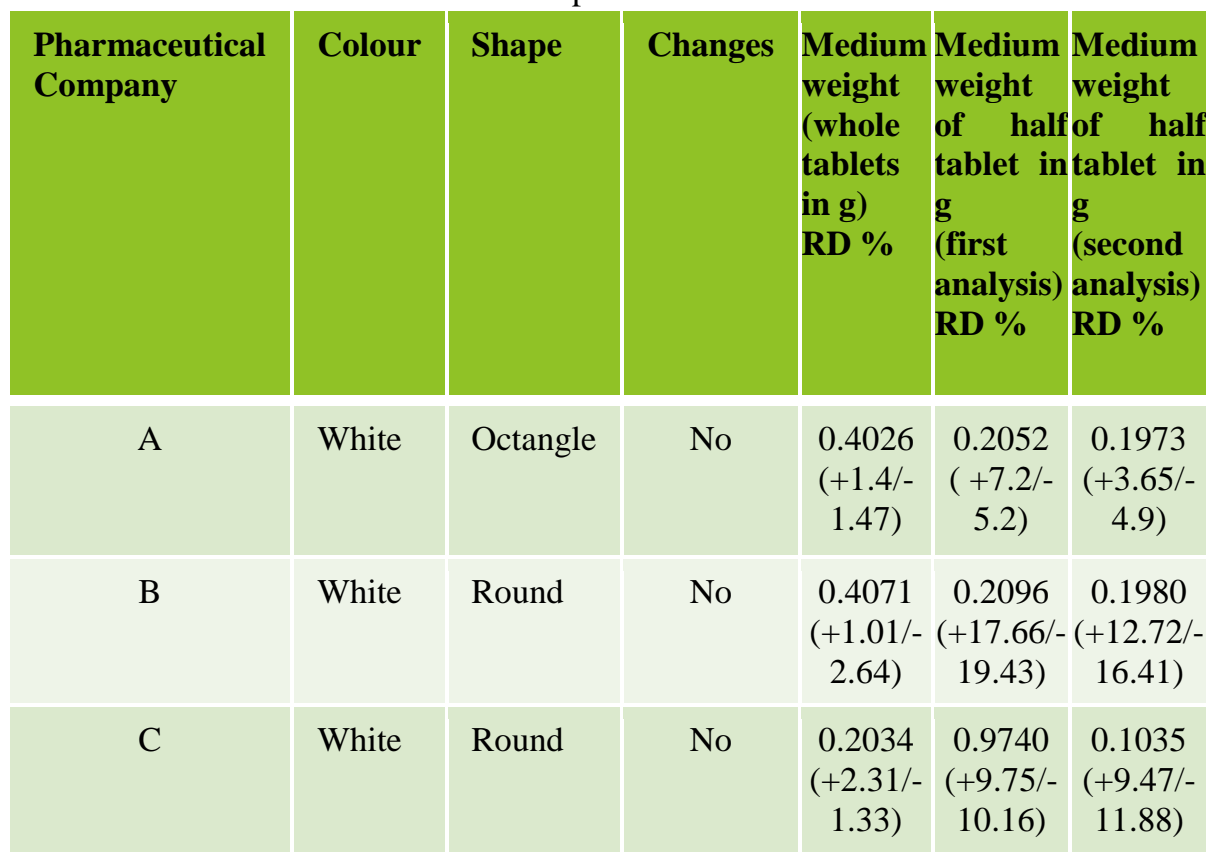

The calibration curve resulted $\mathrm{r}^{2}=1$ as shown in Figure 1.

\section{Calibration curve of the standart}

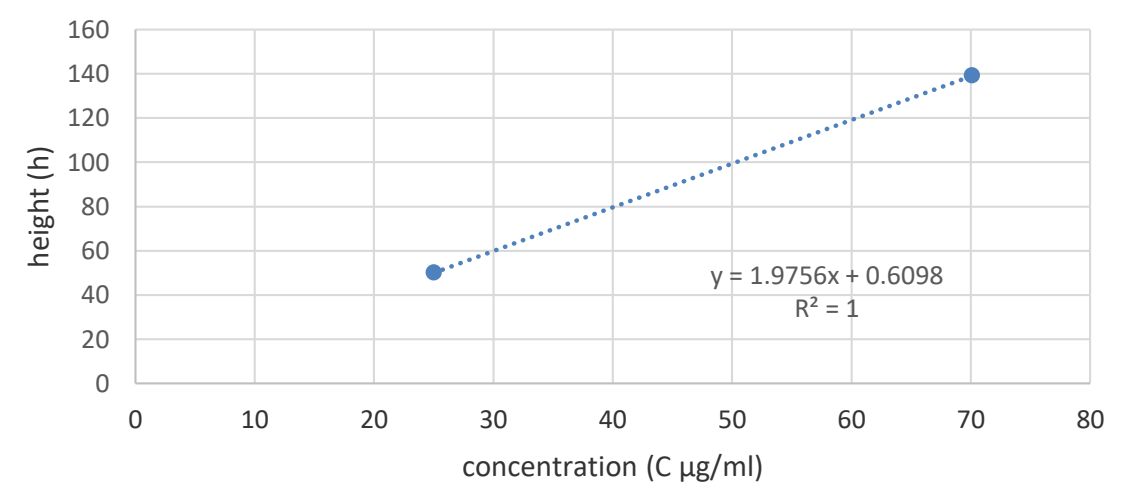

Figure 1. Calibration curve.

From the results obtained, it was noted that there was a decrease in the percentage of the active substance, on halves taken randomly for analysis. The chromatograms per each sample are shown in the figures below. 


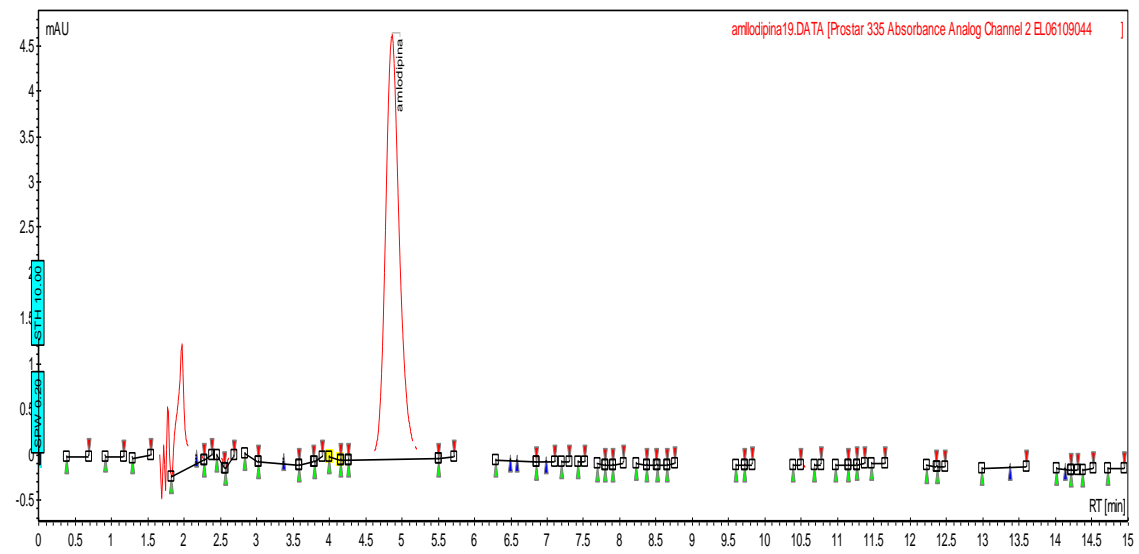

Figure 2. Chromatogram obtained during the analysis of sample A.

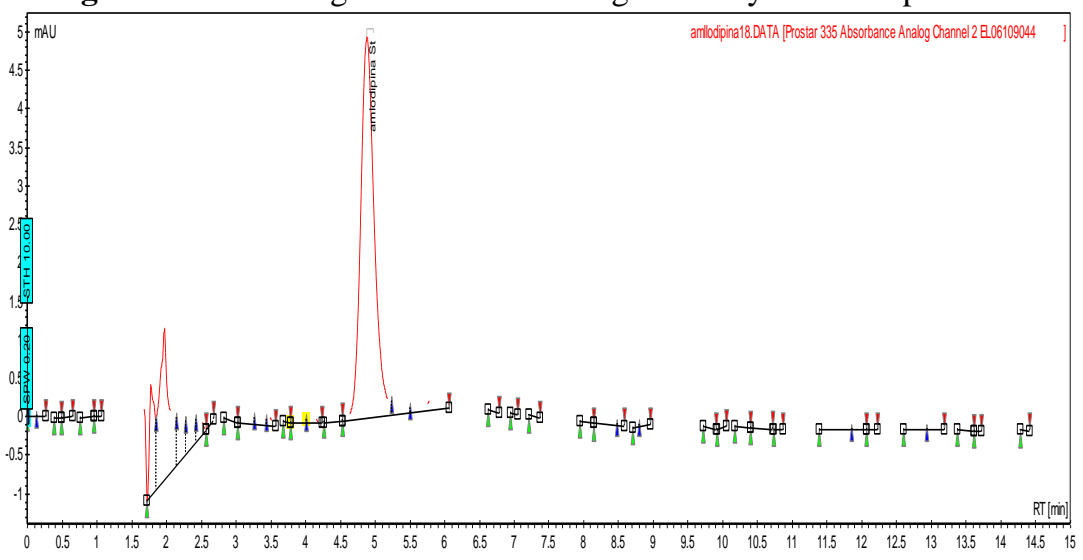

Figure 3. Chromatogram obtained during the analysis of sample B

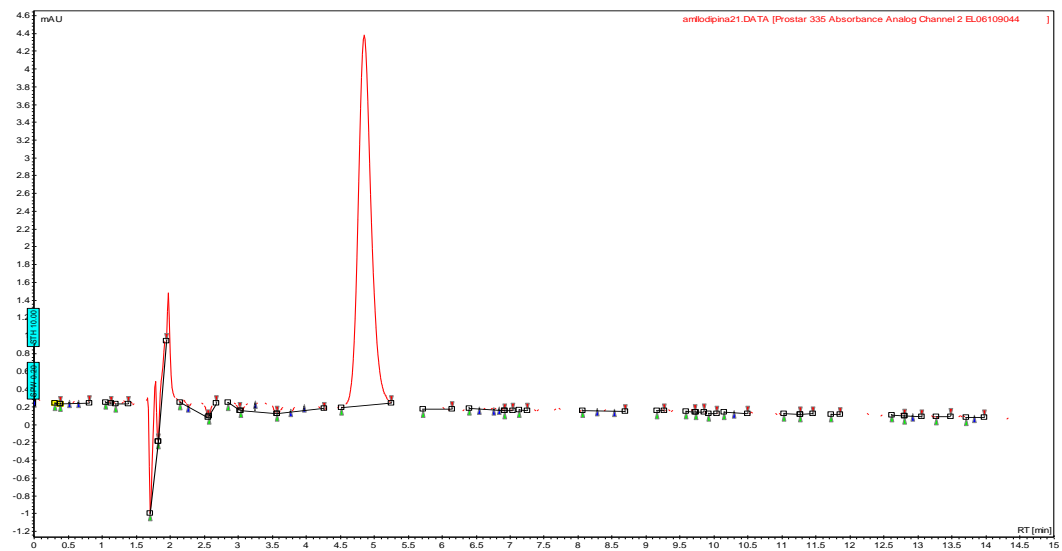

Figure 4. Chromatogram obtained during the analysis of sample $\mathrm{C}$ 
After respective calculations it results that the concentration of the active substance in sample A at the end of the analysis was $83.6 \%$, in sample B $84.37 \%$ and sample C $83.75 \%$.(see Fig. no. 5)

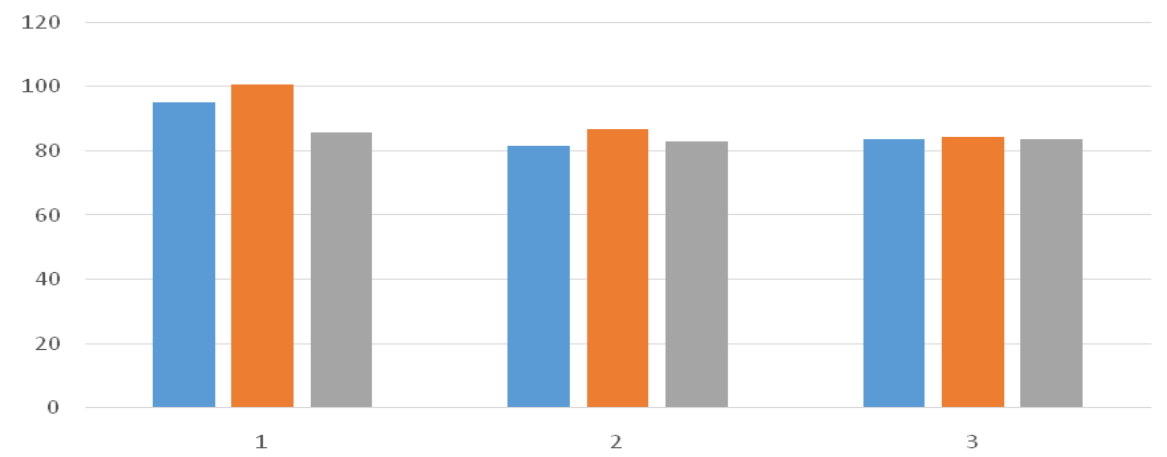

Figure 5. The results obtained from three analysis of tablets after divison, blue belongs to sample A, orange belongs to sample B and grey belongs to sample C).

The level of impurities remain $\leq 2 \%$ conform limits of Eur. $\mathrm{Ph}$.

\section{Discussion}

Tablets keep their organoleptic characteristics for the whole time of conservation. After division it was noticed that only tablets A fullfil the pharmacopoeia criteria on relative deviation $(\mathrm{RD} \pm 7.5$ $\%$ ), the other two productions don't, whilst all undivided tablets fulfill this criteria until the end of the month. This evidence means that the patient will take sometimes more and some times less drug during his/her monthly treatment.

The disintegration time was within pharmacopoeia limits for all 3 productions. As far as it concern impurities there were not noticed significant differences during 4 weeks of the study. Regarding the percentage of active ingredient it was noticed that decreases week after week. Tablets produced by company $\mathrm{C}$ lost the recommended percentage of active ingredient since the first week after division. Tablets produced by company B showed a more stable percentage of active ingredient compared to other two productions.

At the end of the fourth week, the percentage of active ingredient decreases down to approx. $85 \%$ for all 3 productions.

\section{Conclusions}

Based on these results, it is concluded that tablet division is a process that significantly affects the percentage of the tablet's active substance. Reducing the concentration of the active substance implies that the patient does not receive the required dose for treatment and the success of therapy is in doubt. The division of amlodipine tablets is economically convenient, but is a practice that should be avoided and not advised by the healthcare providers. 


\section{Recommendations}

The healthcare specialists should advice their patients to avoid the division of tablets by themselves, to try to get the appropriate form/dosage for his/her therapy. It is very much unadvisable to divide tablets since the beginning of the month and to conserve them like that. Pharmacists, MD's, physicians should advice their patients on how to keep the drug at home. Health authorities should take the appropriate measures to have all registered form/dosages available in the market continously, especially those that are part of the Reimbursement List of Drugs.

\section{References}

1. European Pharmacopoeia 2011

2. http://www.google.ch/patents/US20070260065 Process for preparing amlodipine, US 20070260065 A1

3. http://www.hindawi.com/journals/jphar/2016/8961621/ Journal of Pharmaceutics, (2016), Article ID 8961621, Formulations of Amlodipine: A Review, M. Ali Sheraz, S. F. Ahsan, M.F. Khan, S. Ahmed and I. Ahmad; Baqai Institute of Pharmaceutical Sciences, Baqai Medical University, 51 Deh Tor, Toll Plaza, Super Highway, Gadap Road, Karachi 74600, Pakistan; Received 8 July 2016; Accepted 20 September 2016

4. Investigation of the stability with Bracketing Design in Tablet Form; A. Bozkir, H. C. Cetintas and O. M. Saka; Ankara University, Faculty of Pharmacy, Department of Pharmaceutical Technology, TR-06100 Ankara-Turkey

5. https://www.fsdksh.com.al/images/2016/Lista e Barnave/LBR2016 update 04Gusht/Lista e Barnave te Rimbursueshme 2016.pdf

6. http://www.nps.org.au/australian-prescriber/articles/splitting-tablets-6 Splitting tablets Jennifer L. Marriott and Roger L. Nation; Aust Prescr 2002;25:133-51 Dec 2002 